\title{
Princípios e aplicações de espectroscopia de fluorescência de Raios X (FRX) com instrumentação portátil para estudo de bens culturais
}

Marco Ferretti*

\section{Resumo}

Há cerca de meio século a espectroscopia de fluorescência de raios $X$ (FRX) é uma das técnicas chave no estudo dos materiais de interesse cultural. Pelo menos três razões justificam sua aplicabilidade: a) Trata-se de uma técnica elementar, que permite a identificação dos materiais componentes de um objeto, como também o estudo de sua proveniência e tecnologias de fabricação; b) Não é destrutiva, prestando-se à analise de objetos únicos e de grande relevância artística; c) Adequa-se à instrumentação portátil, o que possibilita seu emprego no interior de museus e de laboratórios de restauro para análise de obras de difícil locomoção, por serem frágeis ou de grandes proporções. Com particular ênfase para os instrumentos portáteis este artigo discute os aspectos gerais da técnica FRX no âmbito de suas possibilidades de emprego e da metodologia de uso. Destaca a particular eficácia do espectrômetro como instrumento adequado para efetuar uma rápida e eficiente seleção preliminar dos materiais que compõem os objetos, que podem vir posteriormente a ser analisados com outras técnicas de caracterização mais sofisticadas. Apresentam-se ainda três estudos de caso sobre análises de ligas de cobre em manufatos antigos: a porta bizantina da Basilica di San Paolo Fuori Mura, em Roma; os objetos do Deposito de Trèstina e as moedas tardo-romanas do Tesouro de Misurata. Demonstra-se que no estudo destes objetos, apesar de não terem sido realizadas medidas quantitativas, foi possível obter de modo não destrutivo dados importantes a respeito das características de algumas partes da estrutura original das peças mencionadas, como é o caso das moedas romanas, sobre as quais as análises fundamentaram importantes estudos históricos que trouxeram novas e relevantes informações a respeito das políticas monetárias da época.

Palavras chave: FRX. Análises não destrutivas. Metais de interesse cultural. 


\title{
Principles and applications of XRF analysis with portable equipment
}

\begin{abstract}
Since about half a century $X$-ray fluorescence (XRF) is a key technique for the investigation of cultural materials. The reasons of its success are at least three: a) it performs elemental analysis, which is essential for the identification of the object's component materials, as well as its provenience and fabrication technologies; b) it is non-destructive, where the analysed objects are in most cases unique and artistically relevant and c) the equipment can be made portable and therefore used inside museums or conservation laboratories on objects that often are too big or too fragile to be moved. With a special regard to portable equipment, this paper discusses general aspects of the XRF technique, such as its range and methodology of use. The particular efficacy of the spectrometer at performing a rapid preliminary selection of materials to be subsequently investigated with more sophisticated techniques is highlighted. Finally three case studies concerned with copper alloys are presented: the byzantine door of the Basilica di San Paolo Fuori Mura in Rome, a group of artifacts from Deposito de Trèstina and the Late-Roman coins of the Misurata Treasury. In the study of these objects, it is shown how it was possible to obtain in a non-destructive way important data concerning the characteristics of some parts of the original structure of the mentioned pieces, although quantitative measurements were not carried out. That is particularly true for the Roman coins, about which the analysis has provided the base for important historical studies that brought new and relevant information concerning the period's monetary policies.
\end{abstract}

Key-words: XRF. Non-destructive analysis. Ancient metals.

\section{A importância do estudo da composição elementar dos materiais de interesse cultural}

O reconhecimento da composição elementar de objetos é de grande interesse para estudos de caráter arqueológico e histórico-artístico, na medida que possibilita o estabelecimento de nexos entre a procedência, a tecnologia dos materiais e as técnicas de fabricação dos manufatos. A avaliação qualitativa dos materiais que 
compõem um objeto, propiciada pelas análises elementares, permite, por exemplo, que se distingam as partes não pertencentes a uma determinada estrutura original (os refazimentos) e, em alguns casos, auxiliam também na identificação de falsificações.

Mais complexos são os exames que dão suporte às intervenções conservativas, para as quais as técnicas de análises elementares, sozinhas, raramente fornecem dados suficientes. Entre os materiais que os estudos de composição elementar fornecem resultados mais significativos estão as cerâmicas, as obsidianas, os metais, as pastas vítreas e as superfícies pictóricas, a saber:

Cerâmicas e obsidianas: Por existir uma estreita relação de composição elementar entre os manufatos e seus materiais de base, é possível identificar locais de escavação (PICON et al, 1971; WILLIAMS-THORPE, 1995) (1), o que pode vir a fornecer dados essenciais sobre centros de produção e vias comerciais relacionados a esses objetos.

Metais e pastas vitreas: Nestes casos, a relação entre a composição dos manufatos com os seus materiais de base não é tão estreita, dificultando sobremaneira estudos de proveniência baseados somente na composição elementar. O conhecimento desta última, todavia, pode fornecer informações relevantes sobre contexto e tecnologia de fabricação (CRADDOCK, 1976; COX; GILLIES, 1986). (2).

Materiais pictóricos: Para grande parte dos materiais pictóricos (alguns suportes, colas, ligantes, pigmentos, vernizes, etc.), devido à sua natureza orgânica, as análises elementares têm pouca utilidade, mas são de grande valia para pigmentos e preparações inorgânicas. Assim, para as obras pictóricas, face da natural heterogeneidade de seus estratos característicos, que podem comportar tanto materiais orgânicos como inorgânicos, a literatura tem demonstrado que em inúmeros casos, o simples emprego de análises qualitativas foi suficiente para a identificação satisfatória dos constituintes das camadas destes estratos (FERRETTI et al, 1991). (3). 


\section{Breve história do uso de FRX para estudo dos materiais de interesse cultural}

A fluorescência $X(F R X)$ é uma técnica de análise elementar que vem sendo usada há aproximadamente meio século para caracterizar os materiais de interesse cultural.

Suas primeiras aplicações neste campo remontam aos anos de 1950, quando espectrômetros com dispersão por comprimento de onda (HALL, 1958) foram utilizados para analisar pequenos objetos metálicos (KRAAY, 1958) (4), vidros (BANKS et al, 1963), jade (HALL, 1964) e pigmentos (GETTENS; FITZHUGH, 1966) (5).

A introdução da focalização nestes sistemas (BANKS; HALL, 1963) permitiu análises de áreas diminutas em amostras complexas, a exemplo das seções estratigráficas das pinturas (STOLOW et al, 1969).

Desde o início essa técnica vem sendo usada de modo não-destrutivo, ainda que, por vezes, pequenas abrasões locais tenham sido necessárias para a obtenção de dados quantitativos (HALL, 1961; CARTER, 1964). As exceções ficam por conta das cerâmicas (PICON et al, 1971), para as quais a necessidade de se obter dados rigorosamente quantitativos impõem a retirada de amostras.

O pleno aproveitamento das potencialidades do FRX como método não destrutivo foi alcançado quando detectores a semicondutores entraram em uso comum (CESAREO et al, 1972; HALL et al, 1973). Em função de sua estrutura compacta foi possível construir sistemas portáteis para realizar análises in situ e, assim, o emprego da fluorescência X pôde ser estendido à análise de qualquer tipo de objeto, independentemente de suas dimensões. Desde então os sistemas portáteis não mudaram muito, ainda que tenham sido experimentadas novas configurações, a exemplo da espectroscopia de raio $X$ com reflexão total (TRXRF) (DEVOS et al, 1995) e o uso de capilares para a obtenção de microfeixes (MILAZZO; CICARDI, 1998; CALVI et al, 1998). Há diversos anos estão também em uso os detectores a semicondutores com resfriamento termoelétrico (LUTZ; PERNICKA, 1996) que melhoraram sensivelmente a portabilidade dos espectrômetros. 


\section{Os princípios físicos da fluorescência $X$}

Os princípios físicos da florescência $X$ são simples e bem conhecidos (JENKINS et al, 1995): é possível induzir transições eletrônicas entre os orbitais mais internos dos átomos utilizando radiações eletromagnéticas de energia adequada (raios $\mathrm{X}$ e raios gama). Essas transições podem resultar na emissão de radiações $X$ de energia característica que permitem a identificação da espécie atômica envolvida na transição e a mensuração da sua abundância. Mais especificamente, neste processo a energia da radiação de fluorescência identifica o elemento, enquanto sua intensidade permite que seja medida sua concentração na amostra analisada mediante uma prévia calibragem.

Destaca-se que a baixa penetração dos raios $X$ de florescência na matéria, da ordem dezenas de microns, em função do elemento florescente e da matriz, limita a informação analítica aos estratos mais superficiais do material estudado, o que constitui uma das limitações desta técnica.

\section{A instrumentação portátil e seu âmbito de emprego}

Do ponto de vista da utilização a instrumentação de FRX pode ser dividida em duas grandes categorias: os espectrômetros de laboratório e os espectrômetros portáteis.

No primeiro caso (JENKINS et al, 1995) tratam-se de instrumentos projetados para potencializar os serviços analíticos: os limites típicos de sensibilidades giram em torno de $10 \mathrm{mg} / \mathrm{kg}$ em função do elemento. Contudo, em virtude das grandes dimensões destes equipamentos, esta alta sensibilidade se dá às custas de uma baixa flexibilidade no seu emprego, e da necessidade de extração de amostras que precisam ser homogeneizadas e reduzidas a uma geometria padrão.

Evidentemente tais procedimentos são incompatíveis com as necessidades de nãodestrutividade e com as geometrias irregulares dos objetos de arqueologia e arte, problemas que foram resolvidos com o desenvolvimento de aparelhos portáteis.

O espectrômetro portátil é um aparelho que pode ser usado in situ e permite aproximação adequada do objeto a analisar (ver Figura 1), garantindo, ao menos por linha de princípio, a não-destrutividade da técnica. No entanto, se a simplificação 
construtiva deste tipo de espectrômetro, necessária para reduzir seu peso e tamanho, por um lado trouxe vantagens evidentes para a conservação dos bens, por outro impôs certos limites em relação à qualidade final das análises que processa, uma vez que os limites de sensibilidade de detecção são 10 - 100 vezes mais altas em relação aos sistemas fixos.
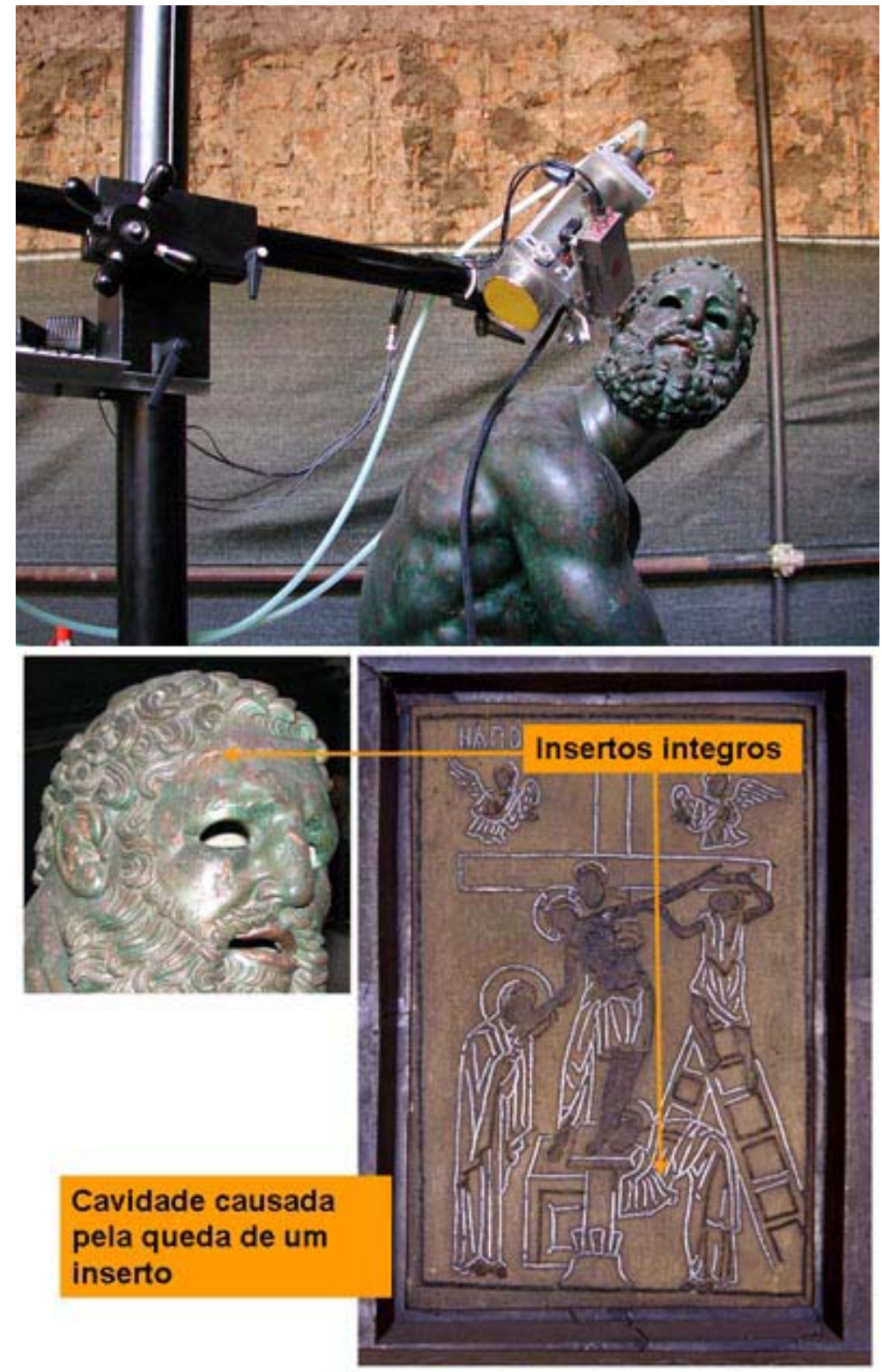

FIGURA1 - Analise não destrutiva com FRX sobre o "Pugilista", estatua de bronze do período helenístico exposta no Museu Nacional de Roma.
FIGURA 1a - Estudo dos insertos metálicos com FRX. O inserto é uma técnica utilizada para obter efeitos cromáticos no metal.Tratase de escavar uma cavidade no metal principal e preenche-lo (usualmente por deformação plástica obtida com martelamentos) com um outro metal de cor diversa.

Do ponto de vista funcional, uma característica fundamental de um dado sistema portátil de FRX é a sua capacidade de excitar de modo eficiente as linhas $\mathrm{K}$ de elementos $\mathrm{Z}$ com número atômico em torno de $50(\mathrm{Ag}, \mathrm{Cd}, \mathrm{Sn}, \mathrm{Sb}, \mathrm{Ba})$, de grande importância para a caracterização dos materiais de interesse cultural. Cabe ao projetista do equipamento a escolha entre privilegiar a capacidade analítica ou a 
portatibilidade. Sustentamos que a portatibilidade deve estar subordinada à capacidade analítica, caso contrário há o risco da obtenção de resultados de qualidade tão baixa a ponto de serem praticamente inúteis ao estudo que se quer realizar.

Independentemente das características de cada espectrômetro, a técnica tem suas limitações intrínsecas, estando entre as mais significativas a espessura do material a ser analisado. Há de se considerar que o material de interesse para a análise encontra-se quase sempre deteriorado na superfície apresentando, em conseqüência, uma composição pouco significativa em relação ao restante do material não deteriorado do mesmo manufato. Em situações assim, evidentemente, não tem sentido falar de análise quantitativa. No caso dos objetos metálicos, problemas como estes no passado eram resolvidos com a remoção dos estratos superficiais até que se atingisse o material não deteriorado. No entanto, parece-nos claro que ao mesmo tempo que este tipo de procedimento pode conferir maior confiabilidade nos resultados analíticos obtidos, contradiz os princípios e motivos do emprego da florescência X: a não-destrutividade dos materiais.

Nesta perspectiva, cumpre considerar também que, em muitas ocasiões, estratos superficiais, ainda que deteriorados, são tudo o que resta da superfície original de um objeto ou, por vezes, constitui-se em positiva barreira protetiva. Portanto, a remoção desses estratos termina danificando e agredindo ainda mais a integridade do objeto, tornando-se mais impraticável quanto mais numerosas forem as análises realizadas.

Um outro modo de enfrentar esse problema de destrutividade é o de renunciar às análises quantitativas, no sentido como são comumente entendidas.

Em muitos casos a questão principal a investigar é se algumas partes do objeto são ou não pertencentes à sua estrutura original, para o que é preciso comparar materiais entre si, o que não demanda obrigatoriamente a realização de análises quantitativas. Se as análises quantitativas se fizerem absolutamente necessárias para um determinado estudo é preferível adotar técnicas mais sensíveis que a florescência $X$, a exemplo da espectroscopia atômica lembrando que, no entanto, é 
uma técnica que requer retirada de amostra. Quando essa necessidade for imperiosa, é fundamental integrar uma técnica analítica quantitativa com um método não destrutivo que permita identificar os pontos realmente significativos do problema a estudar, de modo a retirar somente amostras estritamente indispensáveis de material histórico.

Tais colocações são necessárias para melhor dar a conhecer um método de mensuração que prescinde da abrasão das superfícies, sendo por isso adequado à análise dos metais, particularmente dos bronzes, conforme exporemos a seguir.

O espectrômetro FRX portátil não costuma ser usado para análises quantitativas, mas para comparar materiais entre $\mathrm{si}$, permitindo que se passe das medidas absolutas às medidas relativas, sujeitas por natureza a limitações menos estreitas.
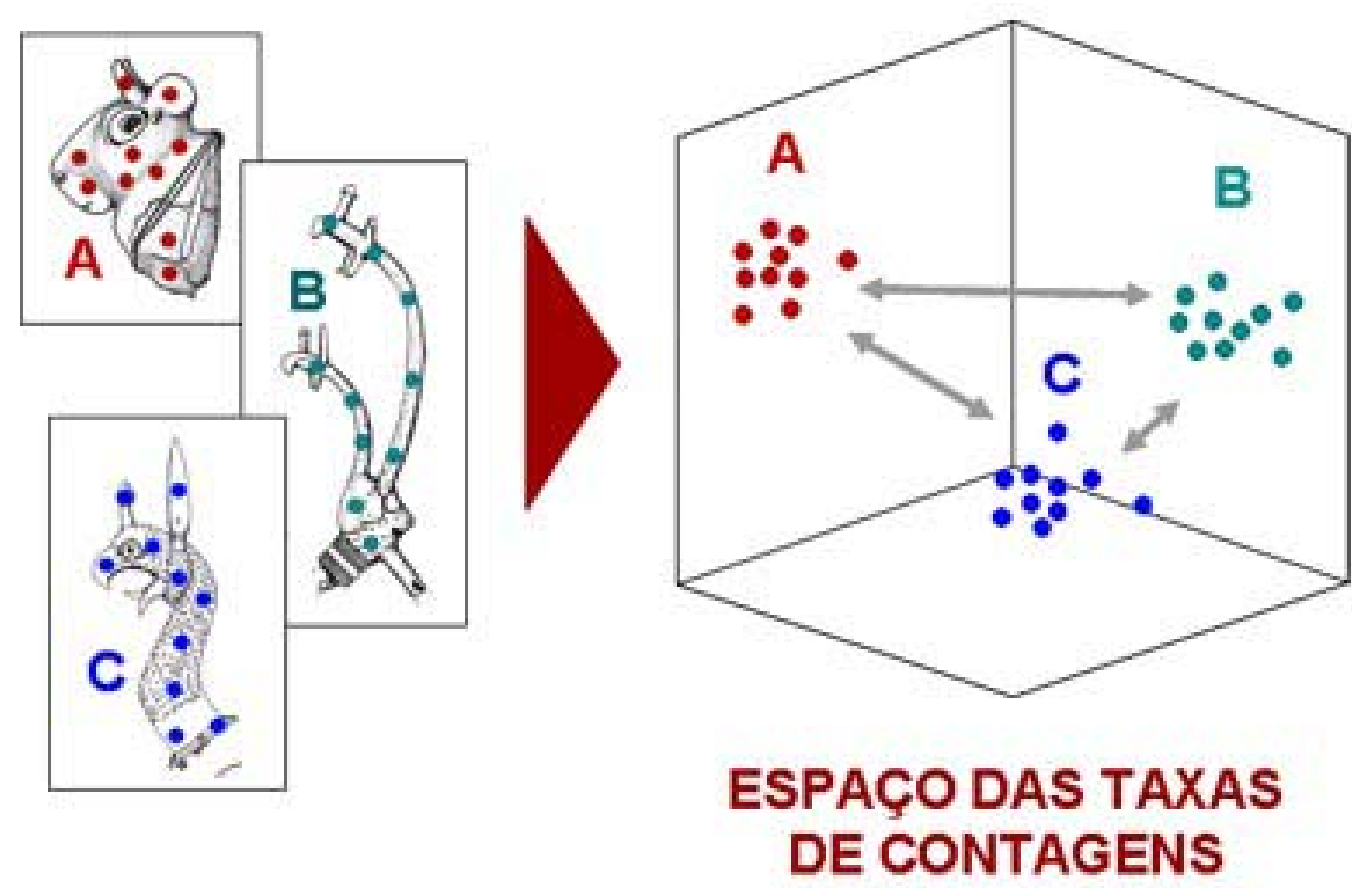

FIGURA 2 - Esquema lógico do método não quantitativo para identificação das composições diversas.

Em relação à Figura 2, imagine-se que a questão seja decidir se os objetos de bronze $A, B$ e $C$ são pertencentes a um mesmo contexto de fabricação, uma vez que são feitos com a mesma liga metálica.

Sobre cada um dos objetos é efetuado um número significativo de medidas sem 
remoção da pátina superficial. Tratando-se de uma técnica não-destrutiva, o número de medidas só é limitado pelo tempo disponível pelo operador.

Se os elementos químicos analisados são $\underline{n}$, é possível representar cada ponto de medida no espaço $n$-dimencional das taxas de contagens, de modo que a liga constitutiva de cada objeto se encontre representada no gráfico por uma nuvem de pontos.

É claro que em razão do modo que é feita a medida, não se separam as informações da pátina daquelas do metal não corroído e, em conseqüência, a nuvem é tão mais difusa, quanto mais variável for a espessura e a composição da pátina. Todavia é sempre possível afirmar que duas ligas são diferentes entre si se o espaço que separa as duas nuvens for significativamente maior que cada uma delas.

Os resultados são ainda mais confiáveis quanto maior for número de elementos analisados e o número de medidas tomadas. $\mathrm{O}$ espectrômetro ideal para este tipo de aplicação deve ser bastante sensível, veloz e de fácil posicionamento sobre os objetos.

Nos parágrafos seguintes apresentam-se três casos de estudo nos quais a fluorescência $x$ foi aplicada para o estudo de manufatos de bronze em combinação com outras técnicas como a espectroscopia atômica e a microscopia eletrônica.

\section{A porta bizantina da Basílica di San Paolo Fuori le Mura, Roma}

Trata-se de uma porta bizantina com decorações e insertos de prata (Figura 3) realizada em Constantinopla no ano de 1070, que ao longo de sua história sofreu alguns refazimentos, além de danos causados por um incêndio. As análises de FRX foram realizadas in situ com um instrumento portátil, ocasião em que foram caracterizadas as partes mais significativas da porta (ANGELUCCl et al, 2001).

As diferentes composições observadas prestaram-se a evidenciar os diversos refazimentos que a porta sofreu ao longo do tempo. Os gráficos de taxas de 
contagens de estanho e zinco ( $\mathrm{Sn}-\mathrm{Zn}$ ) e estanho-antimônio (Sn-Sb) mostram claramente três grupos distintos de ligas (Figura 4).

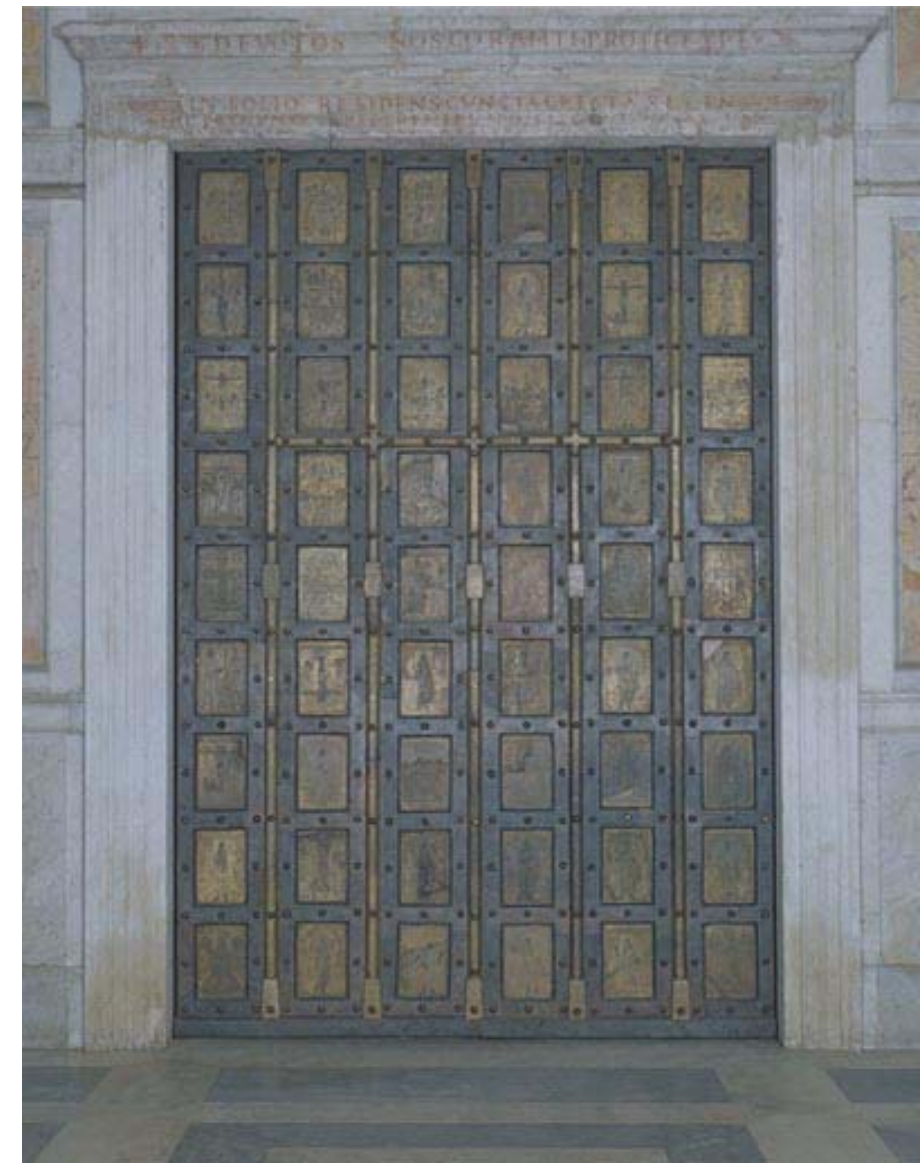

FIGURA 3 - A porta bizantina da Basílica di San Paolo Fuori le Mura, Roma.

O grupo A corresponde a todas as partes consideradas originais, independente do fato de se tratarem de formas, molduras, soldas, rejuntes ou elementos em relevo do grupo, incluindo-se até uma cabeça de prego. Nestas partes foram identificadas quantidade relativamente baixa de $\mathrm{Zn}$ e $\mathrm{Sn}$ e altas de Sb. Já os insertos dos painéis, contatou-se, foram realizados com uma liga de $\mathrm{Ag}-\mathrm{Cu}$.

O grupo B corresponde a trechos do objeto que apresentavam refazimentos antigos. Neles, as medidas revelaram quantidade relativamente elevada de $\mathrm{Sn}$ e Sb e baixa de $\mathrm{Zn}$. As partes em que estes elementos foram identificados correspondem às faixas que recobrem os rejuntes (particularmente as horizontais) e cinco cabeças de prego. Nos painéis correspondentes a esse grupo os insertos não são feitos de metais preciosos como os originais, mas sim com uma liga de $\mathrm{Sn}-\mathrm{Pb}$. 
O grupo $\mathbf{C}$ engloba as partes refeitas por ocasião de uma restauração realizada em 1966, que se revelaram feitas em metal contendo quantidades elevadas de $\mathrm{Zn}$ e baixas de Sn e Sb.

O grupo D compreende algumas outras partes refeitas em 1966, que apresentam quantidade intermediarias de $\mathrm{Zn}$ e $\mathrm{Sn}$ e baixas de $\mathrm{Sb}$.

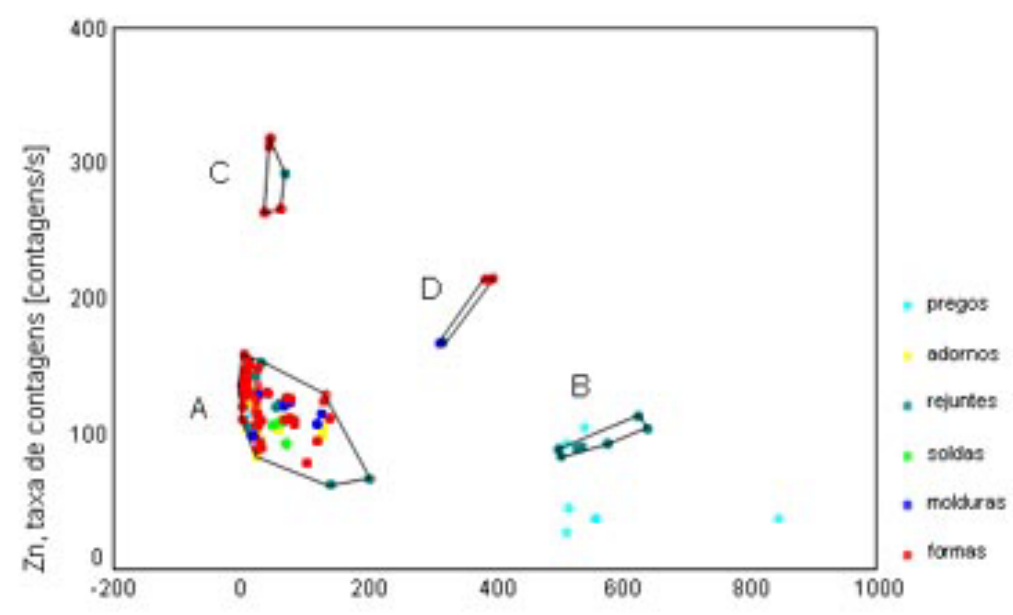

Sn, taxa de contagens [contagens/s]

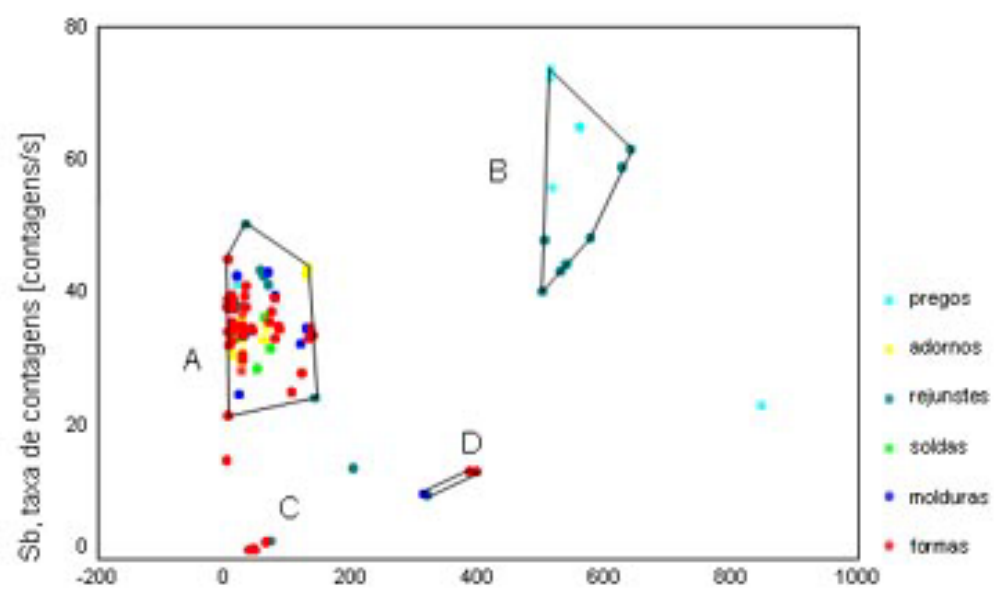

Sn, taxa de contagens [contagens/s]

FIGURA 4 - Medidas de FRX realizadas na Porta di San Paolo: diagrama das taxas de contagens $\mathrm{Sn}-\mathrm{Zn}$ (encima) e Sn-Sb (embaixo).

Após estas análises qualitativas foram realizadas análises quantitativas feitas com espectroscopia atômica que permitiu individualizar um número muito maior de elementos e assim avaliar separadamente os elementos presentes em traço, relacionados aos materiais de base e os principais elementos de liga adicionados deliberadamente e, portanto, associáveis à tecnologia de fundição. A Figura 5 ilustra 
os resultados das análises dos componentes principais dos grupos de elementos em traço e dos grupos de elementos principais; casos identificados em três grupos estudados, a saber:

O grupo A é o que inclui todas as partes consideradas originais: formas, juntas de arremate com seus reforços, elementos em relevo e soldas.

O grupo B inclui alguns arremates e seus acabamentos, especialmente os horizontais e uma cabeça de prego.

O grupo C é mais irregular. Inclui fragmentos de cabeças de prego e faixa inferior.
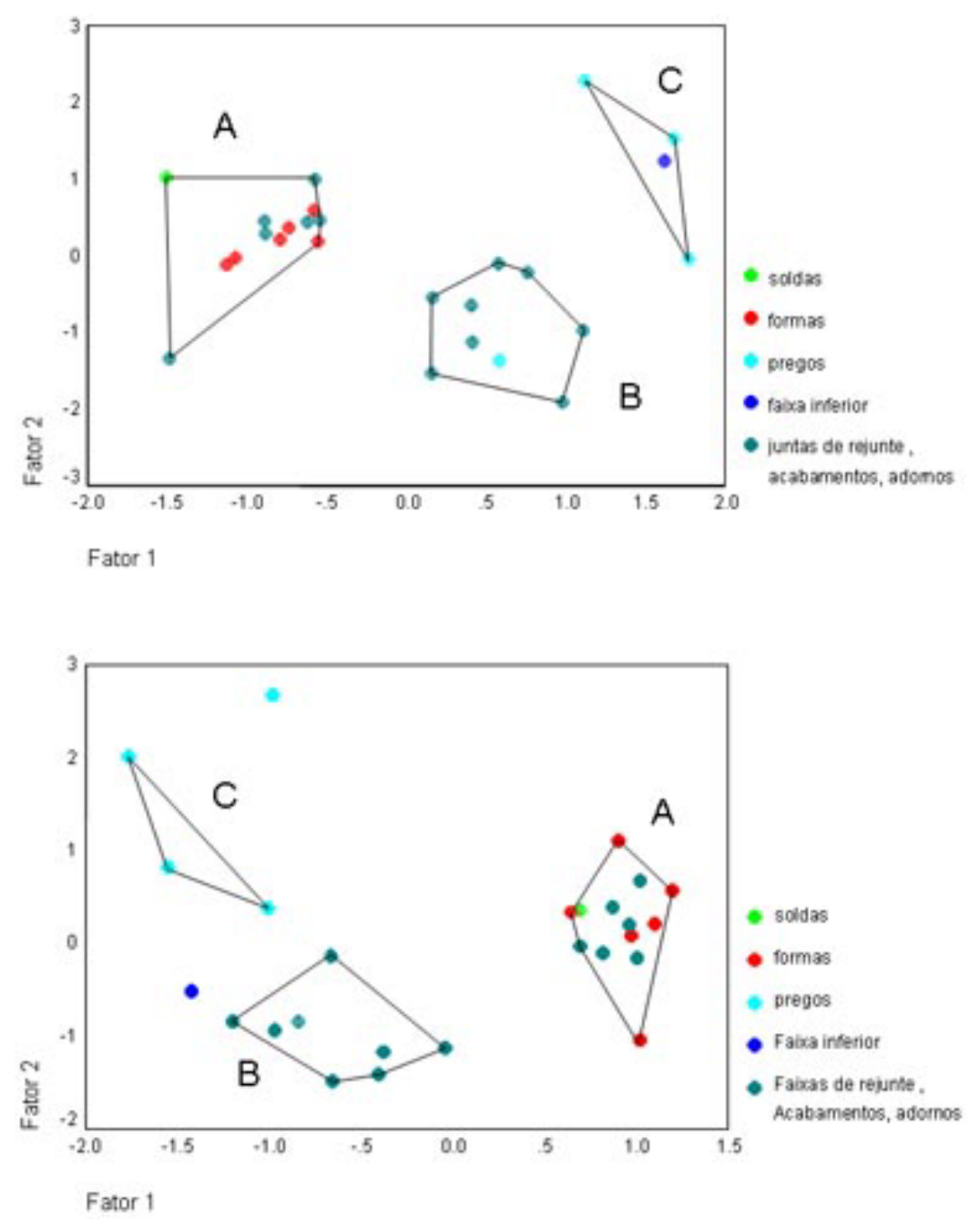

FIGURA 5 - Análises ICPAES realizadas na Porta di San Paolo: análises dos componentes principais. Acima, os elementos em traço Ag, Fe, Sb, Ni, Co, As, Bi. Abaixo, os elementos principais $\mathrm{Pb}$, Sn e $\mathrm{Zn}$. (elementos em traço) (elementos principais)

Desses resultados pôde-se concluir que os resultados da fluorescência $X$ correspondem àqueles obtidos com o emprego de espectroscopia atômica. As diferentes composições entre as ligas evidenciaram as alterações relacionadas com a história da porta. 
Constatou-se, por exemplo, que as partes originais da porta realizadas com uma mesma liga com baixa porcentagem de estanho e com concentrações de As, Ni e Sb são coerentes com a composição dos minerais polimetálicos da Anatólia (PALMIERI et al, 1995; PALMIERI, 1999) (7). Os insertos originais são feitos com uma liga de Ag-Cu. Identificaram-se também índices elevados de Sn nos reparos antigos correspondentes ao arremate horizontal; sobre eles os insertos são feitos com uma liga de $\mathrm{Sn}-\mathrm{Pb}$. Por fim, nas partes relativas ao restauro realizado em 1966 verificaram-se elevados índices de $\mathrm{Zn}$.

\section{O depósito de Trèstina}

O "depósito de Trèstina" corresponde a um grupo de objetos heterogêneos de bronze, com datação atribuída aos séculos VII-VI aC, de proveniência incerta, que foram descobertos em 1878-79 durante trabalhos agrícolas em Trèstina (cidade de Castello, Itália Central). Com as análises destes objetos variados visou-se confirmar o pertencimento de diversas peças a um mesmo objeto complexo, formado por um trípode que sustenta um caldeirão, e verificar sua eventual diferença em relação aos outros objetos do depósito (FERRETTI et al, 2003). Para tanto, as partes do trípode, os adereços e alças em forma de grifo e as alças de argola foram analisadas primeiro com fluorescência $X$ e depois com espectroscopia atômica (ICP- AES) (Figuras 6 a-b-c-d).

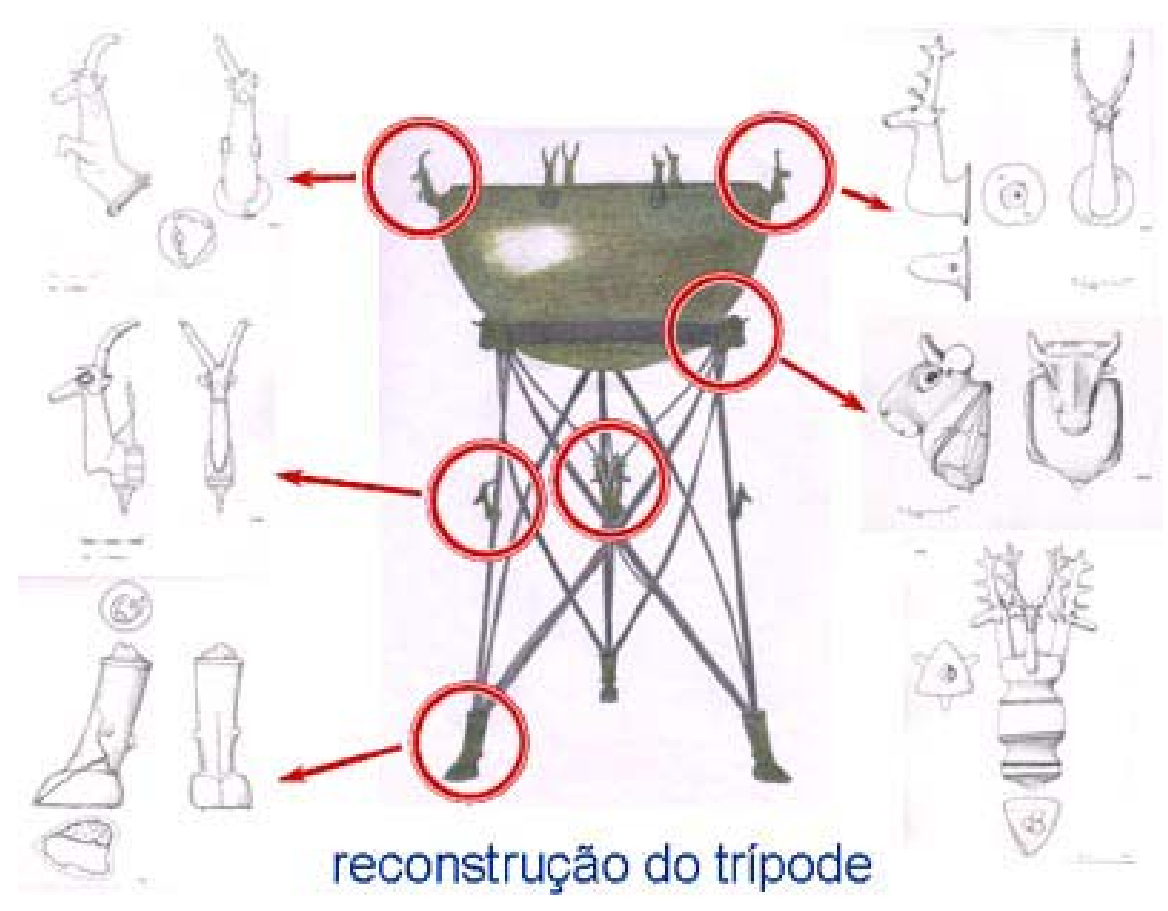

FIGURA 6a - O depósito de Trèstina, parte do trípode 


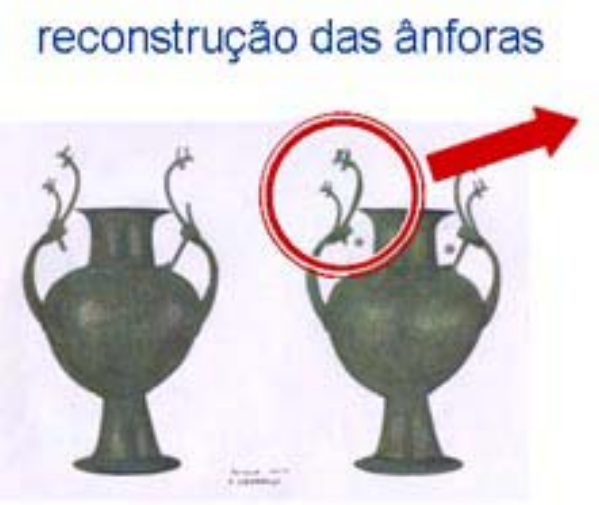

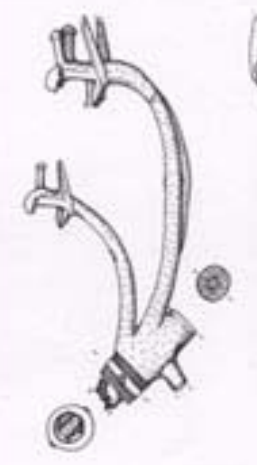

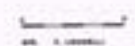

FIGURA 6b - O depósito de Trèstina: as alças em forma de grifo reconstrução do caldeirão
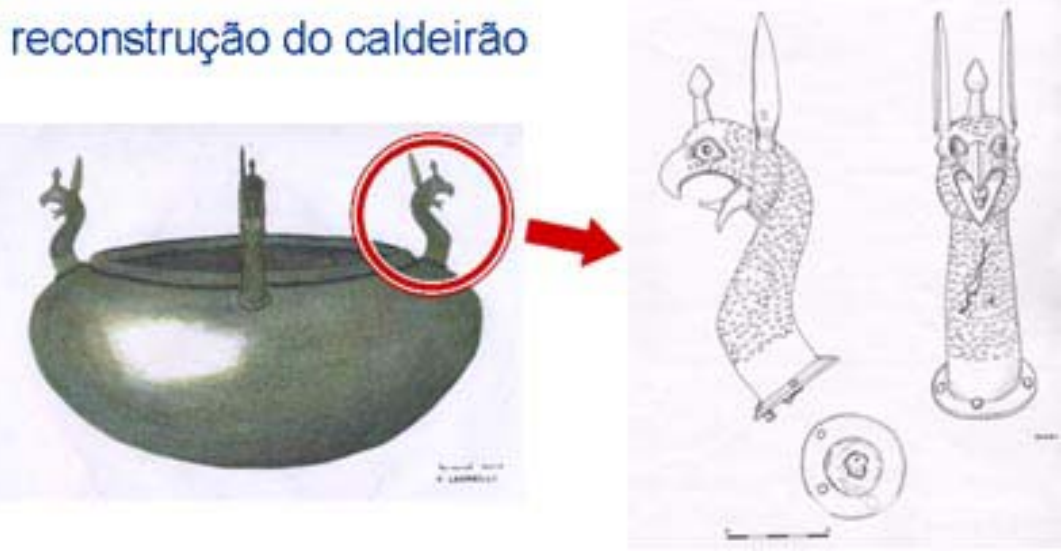

FIGURA 6c - O depósito de Trèstina:adereços em forma de grifo
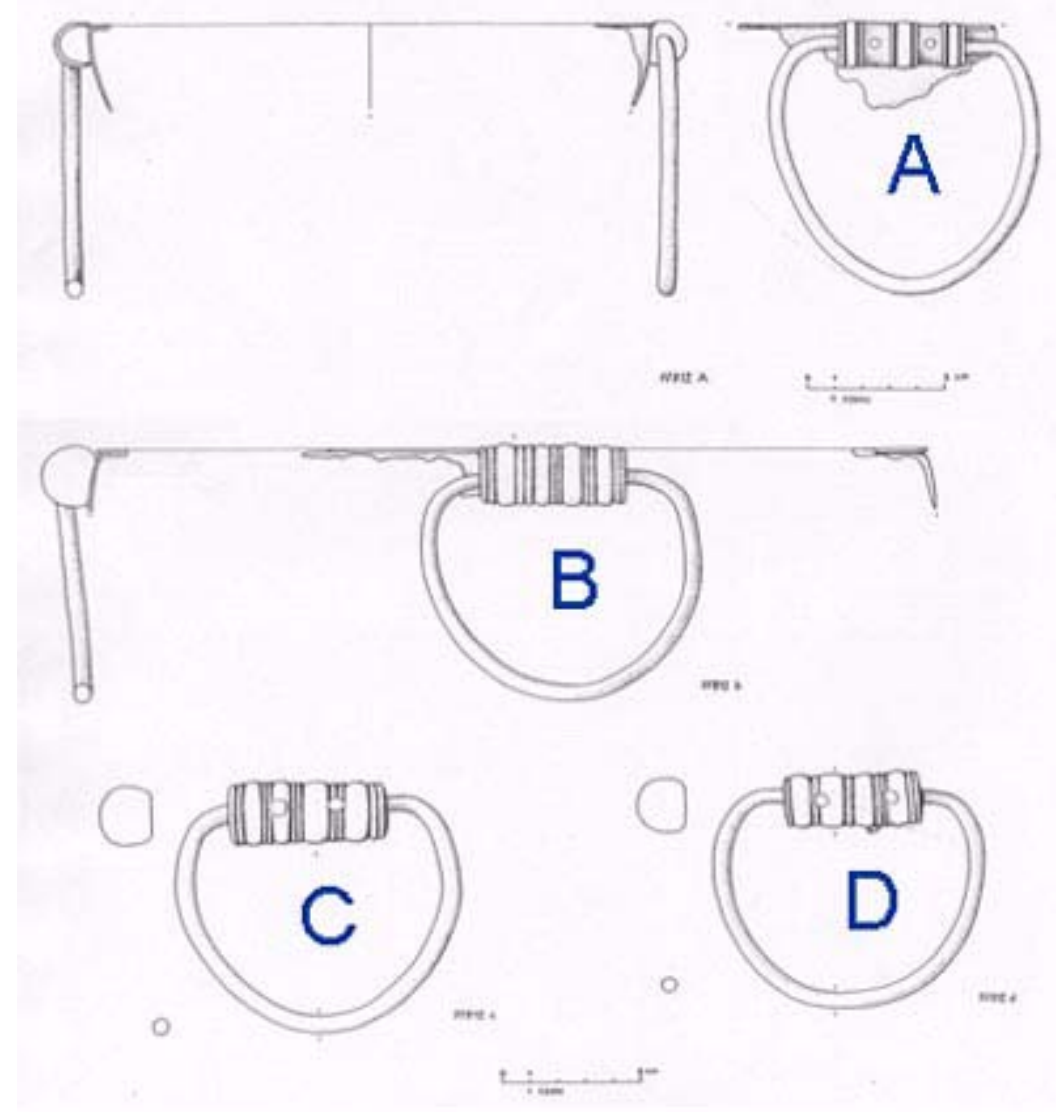

FIGURA 6d - O depósito de Trèstina: as alças de argola 
As análises com FRX foram feitas in situ com espectrômetro portátil. A Figura 7 mostra a comparação da composição feita entre a trípode e as outras peças (alças e adereços) adotando-se para interpretação dos resultados o método de análise das componentes principais aplicado à intensidade das taxas de contagens.

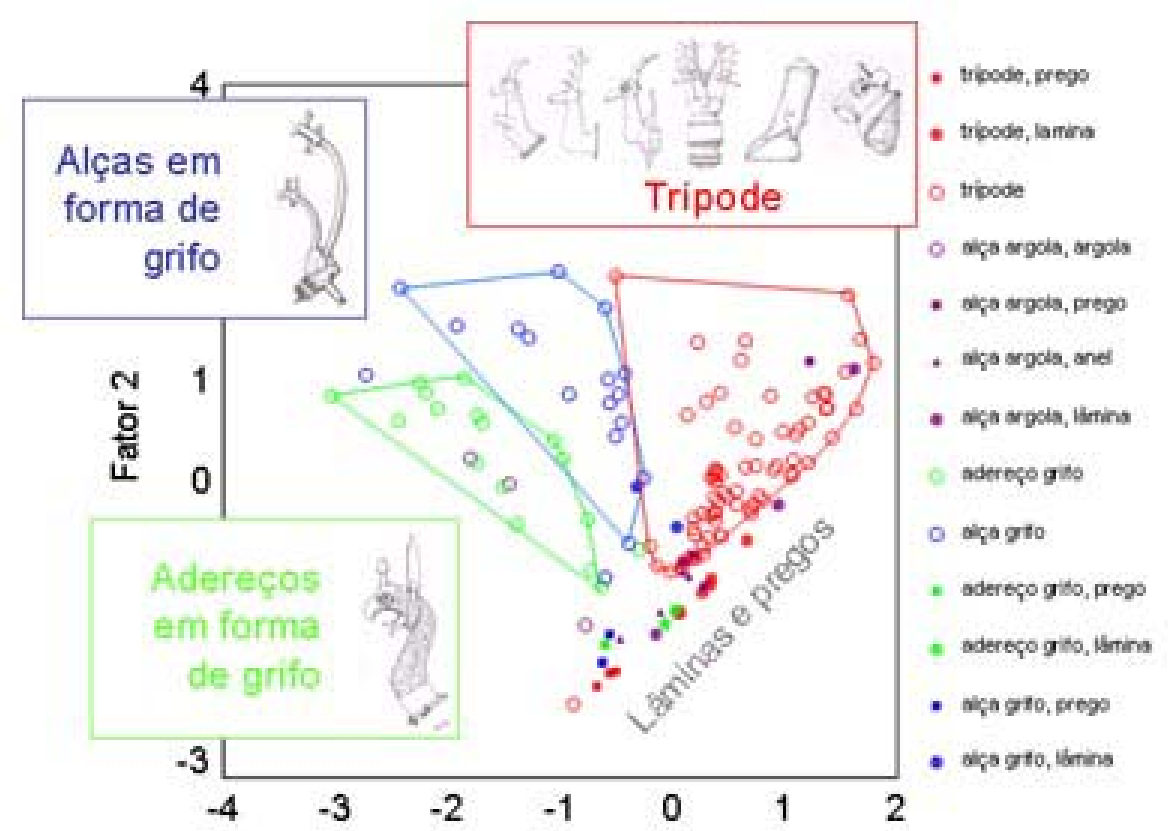

Fator 1

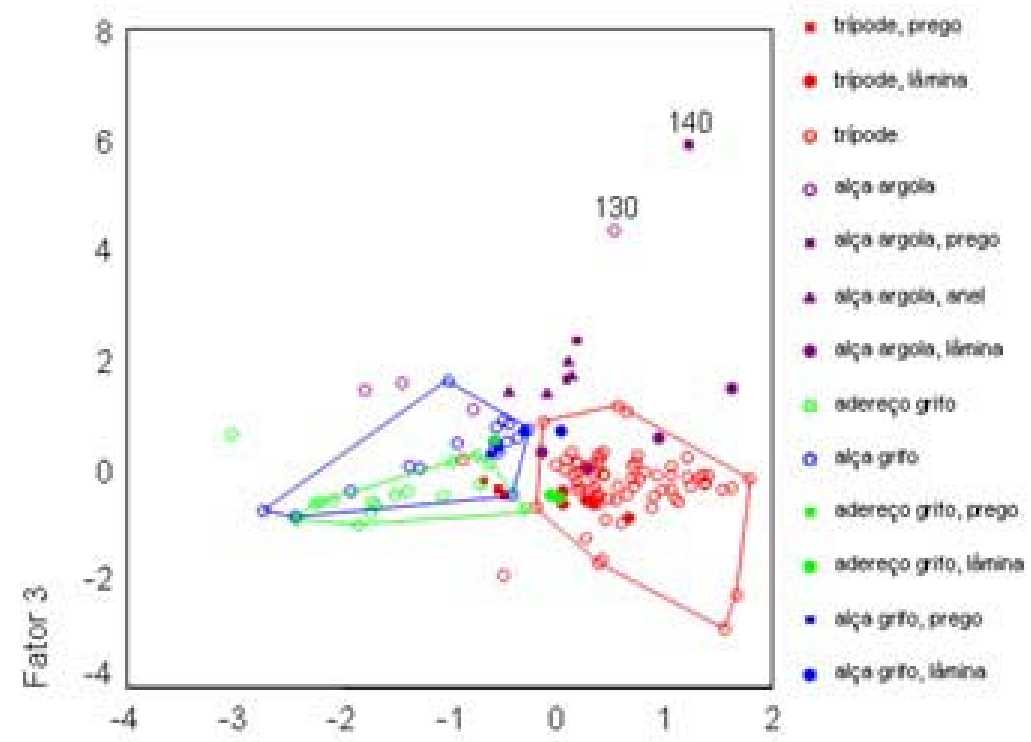

Fator 1

FIGURA 7 - As medidas FRX feitas nos objetos do depósito de Trèstina: trípode, adereços e alças em forma de grifo e as alças de argola. Os gráficos mostram: acima, as componentes principais 1 e 2 ; abaixo as componentes principais 1 e 3 . 
Conforme se observa na Figura 8, a espectroscopia atômica forneceu resultados bastante coerentes com os da fluorescência $X$, tanto para os elementos em traço como para os elementos principais (Figura 8). Destacamos que as partes do trípode, com baixa quantidade de $\mathrm{Pb}$, se distinguem de todos os outros objetos analisados.

O resultado conclusivo é que todas as partes do trípode resultam de um mesmo contexto de produção. Já os grupos restantes, representados pelos adereços e alças, mostraram ter entre si e em relação ao trípode diferenças de composição muito acentuadas que induzem à hipótese de pertencer cada um a um contexto de fabricação diverso.

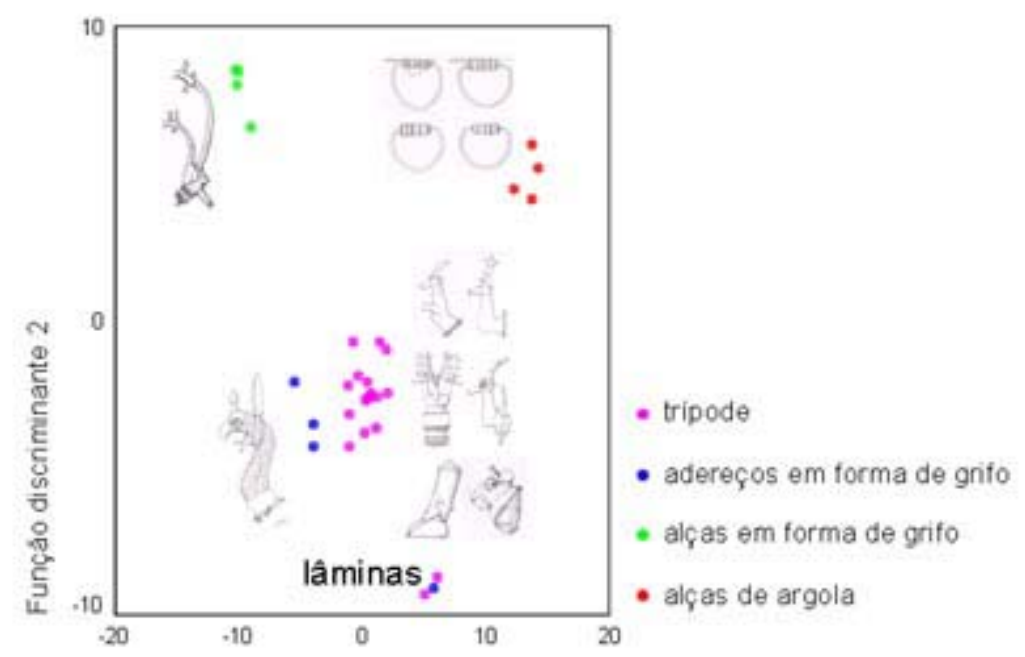

Funçăo discriminarte 1

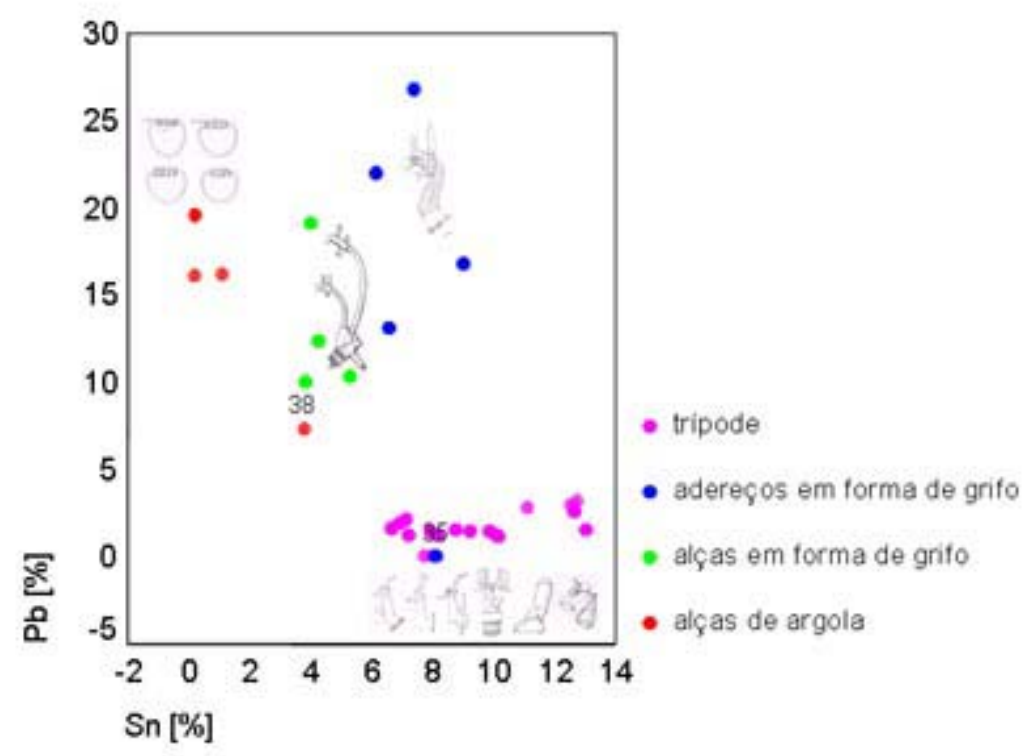

FIGURA 8 - Análise de ECP-ARS no trípode, adereços e alças em forma de grifo e as alças de argola. No gráfico superior os resultados das análises discriminantes sobre os elementos As, Zn, Sb,Co, Ni, $\mathrm{Fe}, \mathrm{Bi}, \mathrm{Ag}$ em traço. No gráfico inferior estão representados os elementos principais: diagrama $\mathrm{Sn}-\mathrm{Pb}$. 


\section{As moedas do tardo império romano do Tesouro de Misurata}

O chamado Tesouro de Misurata, atualmente sob a custódia do Museu Arqueológico de Leptis Magna, na Líbia, é considerado o maior tesouro numismático do mundo antigo.

É composto por cerca de 108.000 folles (moedas de bronze contendo pequena quantidade de prata, recobertas por fino estrato de prata) cunhadas entre o ano de 294 e 333 d.C.
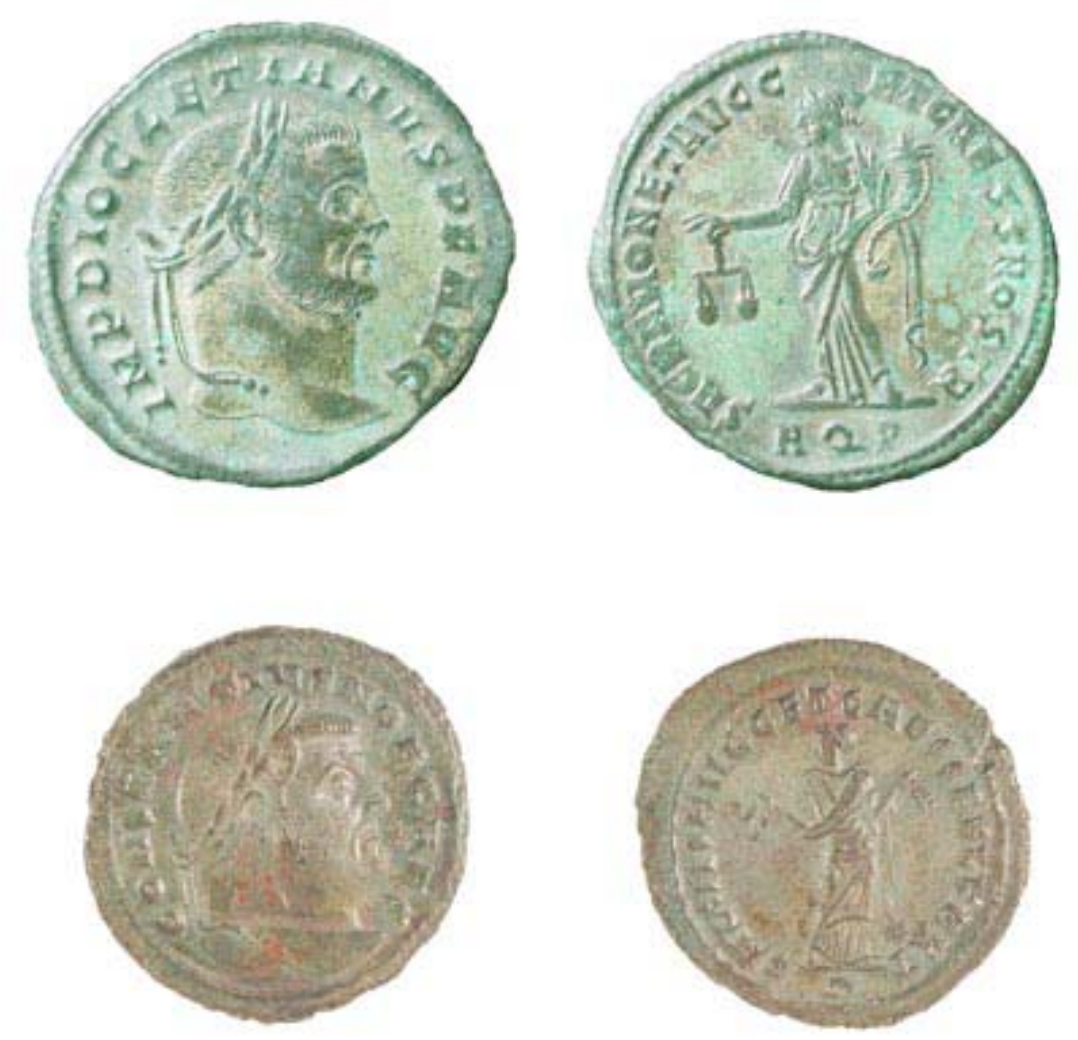

FIGURA 9 - Exemplos de folles emitidas pelo imperador Diocleciano (em cima) e imperador Constantino (embaixo).

A quantidade de peças e seu excelente estado de conservação oferecem condições ideais para estudos sobre a circulação monetária na Tripolitania no tardo império romano, a respeito das variações dos valores reais em relação ao valor nominal e tecnologias de fabricação (CAMPANELLA et al, 2004).

Realizaram-se preliminarmente diversas análises de fluorescência $X$ para verificação da viabilidade e utilidade das analises in situ. A escolha da técnica deu-se em razão da sua não-destrutividade, pela rapidez das medidas que possibilita e pela mobilidade propiciada pelo desenho do instrumento portátil; esses eram requisitos 
fundamentais para viabilizar o grande número de analises necessárias para os estudos de caráter estatístico pretendidos, uma vez que as peças não podiam ser levadas para a Itália.

Não obstante experiências anteriores indicassem que análises de FRX em moedas fossem problemáticas, neste caso específico verificou-se que as taxas de contagens, particularmente as de prata, puderam ser utilizadas para confrontar a emissão e a origem das diversas das moedas que compunham o tesouro. O estrato superficial - fino e descontínuo - influenciou pouco a medida, o que permite uma correlação estreita entre as taxas de contagens e a concentração de prata na liga, que dá o valor real da moeda. A Figura 10 mostra os valores médios e os desvios padrão das taxas de contagens da prata pelas várias emissões das casas de moeda de Roma.

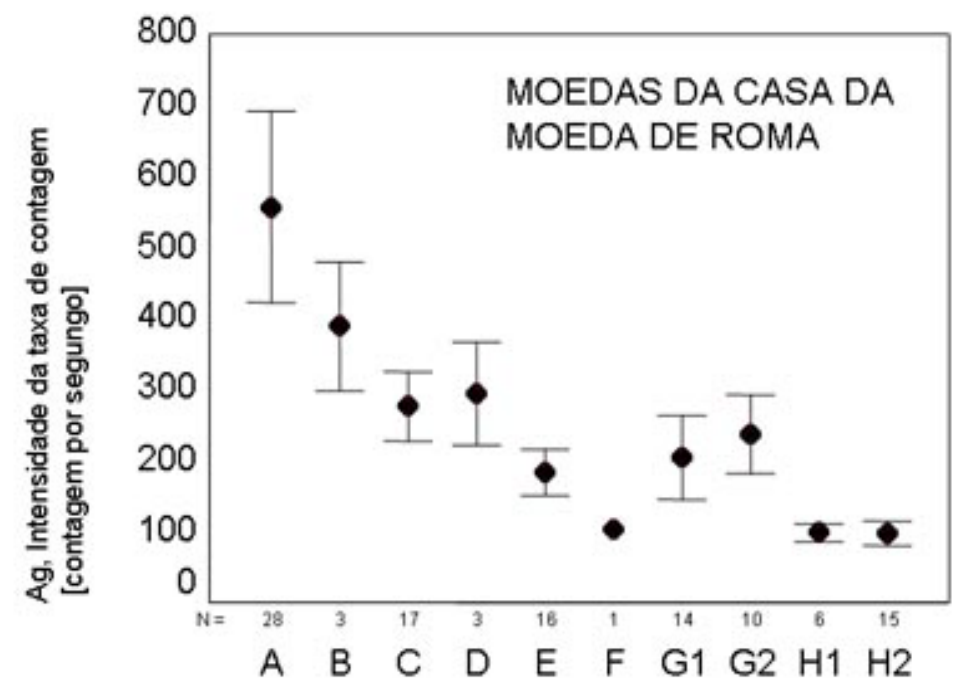

Emissão

\begin{tabular}{|l|c|c|}
\hline \multicolumn{1}{|c|}{ EMISSÃO } & ANO & ID \\
\hline GENIO POPVLI ROMANI & $294-300$ & A \\
\hline SACRA MON VRB AVGG ET CAESS NN & $300-302$ & B \\
\hline SAC MON VRB AVGG ET CAESS NN & $302-306$ & C \\
\hline PROVIDENT DEORVM QVIES AVGG & $305-306$ & D \\
\hline CONSERV VRB SVAE & $307-312$ & E \\
\hline MARTI CONSERVAT AVGN & $310-311$ & F \\
\hline CAESARVM NOSTRORVM & $320-322$ & G1 \\
\hline DN CONSTANTINI MAX AVG/ VOT XX & $320-322$ & G2 \\
\hline CONSTANTINOPOLIS & $330-333$ & H1 \\
\hline VRBS ROMA & $330-333$ & H2 \\
\hline
\end{tabular}

FIGURA 10 - Medidas de FRX no Tesouro de Misurata. Andamento das taxas de contagens da Ag para diversas emissões (identificadas na tabela) da Casa da Moeda de Roma. 
Observa-se imediatamente que, à parte as condições superficiais de variabilidade entre uma moeda e outra, as flutuações são pequenas; isso significa que o teor da prata era cuidadosamente controlado pela casa da moeda.

Observa-se ainda que no período estudado (294-333 d.C), a quantidade de prata, e portanto, o valor real da moeda, diminui progressivamente em relação ao seu valor nominal, conforme atestam estudos precedentes (KLOCKENKÄMPER et al, 1999).

Outras técnicas somaram-se às análises de florescência $\mathrm{x}$ permitindo-nos estudar melhor os aspectos analíticos e micro-estruturais das ligas e os produtos de corrosão, e a microscopia forneceu dados importantes sobre o processo de prateação das folles.

Há muito ainda a pesquisar, mas os resultados obtidos até agora, em particular da coexistência de $\mathrm{Ag}$ e $\mathrm{Pb}$ nas segregações (Figura 11), levam a crer em um mecanismo (COPE, 1972) de transporte para a superfície da prata da liga por conta do chumbo. As observações relativas à distribuição da prata confirmam que os estratos superficiais são finos e muito descontínuos.

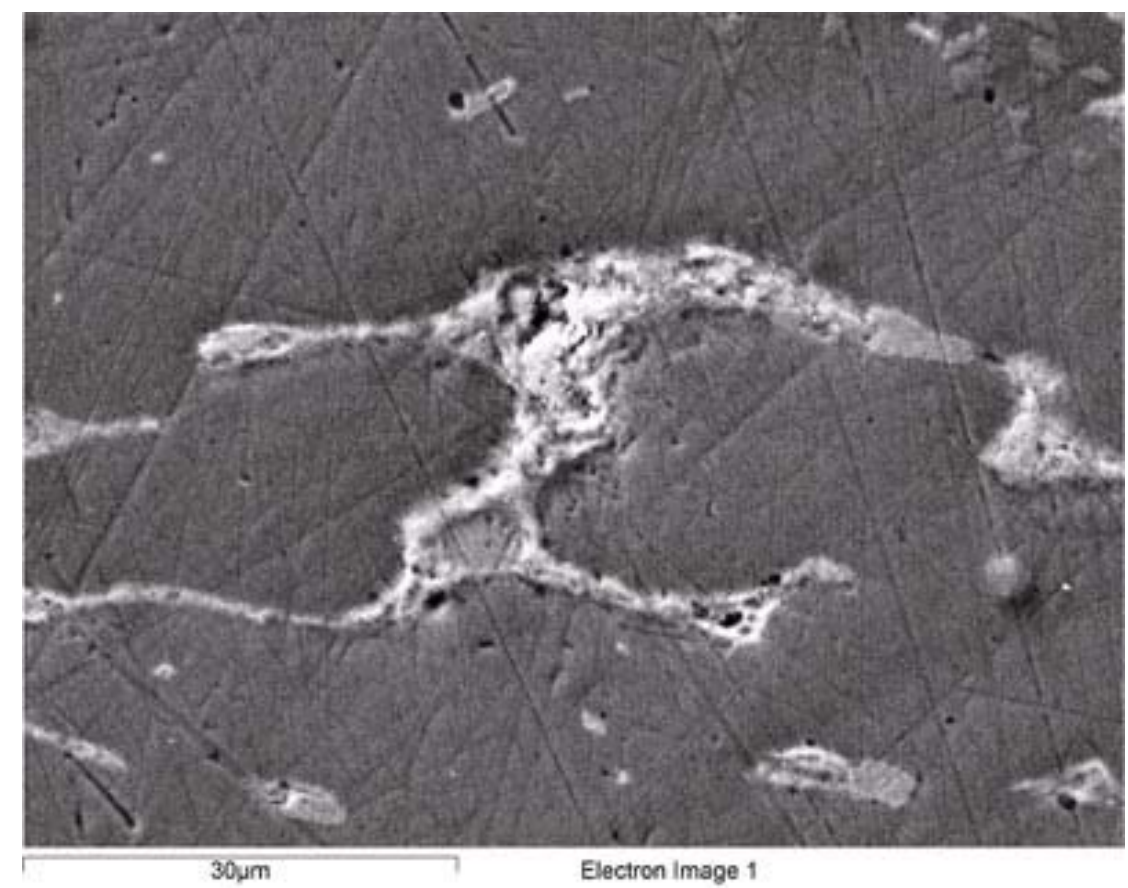

FIGURA 11 - Imagem de microscopia eletrônica de um follis: coexistência de $\mathrm{Pb}$ e $\mathrm{Ag}$ no interior da mesma segregação. 


\section{Conclusões}

Como conclusão deste artigo resumimos as características principais e o âmbito de emprego otimizado da fluorescência $X$.

Trata-se de um método particularmente eficaz e versátil para análises elementares de grande parte dos materiais de interesse arqueológico e histórico-artístico. Suas características peculiares são a rapidez e a não destrutividade das análises que processa, destacando-se também pela sensibilidade aos efeitos de superfície. Efeitos estes que, a exemplo da corrosão, costumam obstaculizar as possibilidades de análises quantitativas, a menos que sejam feitas pequenas abrasões superficiais.

Reiteramos que na maioria dos casos de estudo aquilo que realmente interessa é distinguir materiais diversos entre si e identificar eventuais partes não originais de um dado objeto. Para tanto, pode-se renunciar, sem grandes prejuízos, às medidas quantitativas em favor das medidas relativas que são exeqüíveis sem a remoção de estratos superficiais, respeitando efetivamente a integridade dos artefatos e obras que nos propomos a estudar.

Em prol da melhor conservação dos bens culturais deve-se considerar a possibilidade de usar um espectrômetro portátil para orientar eventuais planejamentos de retiradas de amostras, de modo a identificar de fato as partes mais significativas, reduzindo assim a amostragem a um número mínimo necessário.

\section{Notas}

(1) Ver os artigos: PICON et al, 1975; BALLIÉ; STERN, 1984; SCHNEIDER et al, 1980; SCHNEIDER, 1989, na bibliografia deste texto.

(2) Destacamos os seguintes artigos: CRADDOCK, 1977; CRADDOCK, 1978; CESAREO et al, 1984; SOPRINTENDENZA ARCHEOLOGICA PER LA TOSCANA, 1984; CRADDOCK, 1985; RIEDERER, 1996; HENDERSON, 1989; FREESTONE, 1991; FREESTONE, 1993; BRILL, 1999; FERRETTI et al, 1999.

(3) Ver FERRETTI et al, 1994, na bibliografia deste artigo.

(4) Sobre o argumento destacamos os seguintes textos: SUTHERLAND et al, 1961; HALL; ROBERTS, 1962. 
(5) Ver também os artigos: PLESTERS, 1966; GETTENS et al, 1967; KÜHN, 1968; MUHLETHALER et al, 1969 , constantes na bibliografia.

(6) Destacamos os seguintes artigos da bibliografia: BUCHANAN; TSAI, 1974; GILFRICH, 1989; KELLEY et al, 1994; MALMQVIST, 1986.

(7) Tratam-se de estudos sobre os primórdios da metalurgia na Anatólia (Turquia) que possibilitaram a identificação da "impressão digital”, ou seja, da composição característica dos minerais brutos locais.

\section{Referências bibliográficas}

ANGELUCCI, S.; DIANA, M.; FERRETTI, M.; GUIDO, S.; MOIOLI, P.; PALMIERI, A. The Bizantine door in the basilica of St. Paul out of the walls in Rome: compositional study of the alloys and interpretation of the results in view of its restoration. In: METAL 2001, Santiago. Proceedings... Santiago: [s.n.], 2004. p. 104-111. (Seminário realizado em Santiago, de 2 a 6 de abril de 2001).

BALLIÉ, P.J.; STERN, W.B. Non-destructive surface analysls of Roman terra sigillata: a possible tool in provenance studies?. Archaeometry, [s.I.], v. 26, p. 62-68, 1984.

BANKS, M.; ELPHINSTONE, N; HALL, E.T. Bristol blue glass. Archaeometry, v. 6, p. 26-30, 1963.

BANKS, M.S.; HALL, E.T. X-ray fluorescent analysis in archaeology: the 'milliprobe'. Archaeometry, v. 6, p. 31-36, 1963.

BRILL, R.H. Chemical analyses of early glasses. New York: Corning, 1999.

BUCHANAN, E.B.; TSAI, F.C. Study of the precision of an X-ray fluorescence spectrometric determination. Anal. Chem., v. 46, p.1701-1704, 1974.

CALVI, G.; DI MAURO, F.; PAPPALARDO, L.; ROMANO, F.P. The X-ray microbeam spectrometer at LNS of Catania. In: EDXRS98 - EUROPEAN CONFERENCE ON ENERGY DISPERSIVE X-RAY SPECTROMETRY, 1998, Bologna. Proceedings... Bologna: [s.n.], 1998. p. 7-12. (Seminário realizado em Bologna, de 7 a 12 de junho de 1998).

CAMPANELLA, L.; CHICCO, F.; FERRETTI, M.; GARRAFFO, S. II Tesoro di Misurata: un cantiere permanente di ricerca sulla monetazione nel Tardo Impero Romano. In: CONGRESSO NAZIONALE AIAR, 3., 2004, Bressanone. L'archeometria in Italia: la scienza per i Beni Culturali. Bressanone: [s.n.], 2005. p. $357-362$. (Seminário realizado em Bressanone, de 11 a 12 de fevereiro de 2004).

CARTER, G.F. Preparation of ancient coins for accurate x-ray fluorescence analysis. Archaeometry, v. 7, p. 106113, 1964. 
CESAREO, R.; FRAZZOLI, F.V.; MANCINI, C.; SCIUTI, S.; MARABELLI, M.; MORA, P.; ROTONDI, P.; URBANI, G. Non-Destructive Analysis of Chemical Elements in Paintings and Enamels. Archaeometry, v. 14, p. 65-78, 1972.

CESAREO, R.; FERRETTI, M.; GUIDA, G.; MARABELLI, M. Le leghe: i risultati. In: Marco Aurelio - Mostra di Cantiere. Roma: Arti Grafiche Pedanesi, 1984. p. 43.

COPE, L. H. Surface-silvered Ancient Coins. In: HALL, E. T.; METCALF, D. M. (eds). Methods of chemical and metallurgical Investigation of ancient coinage. London: RNS - Royal Numismatic Society, 1972. p. 261-278. (Special Publication, 8).

COX, G.A.; GILLIES, K.J.S. The x-ray fluorescence analysis of medieval durable blue soda glass from York Minster. Archaeometry, v. 28, p. 57-68, 1986.

CRADDOCK, P.T. The composition of copper alloys used by the Greek, Etruscan and Roman civilizations. 1 The Greeks before the Archaic Period. Journal of Archaeological Science, v. 3, n. 2, 1976.

CRADDOCK, P.T. The composition of copper alloys used by the Greek, Etruscan and Roman civilizations. 2 The Archaic, Classical and Hellenistic Greeks. Journal of Archaeological Science, v. 4, n. 2, 1977.

CRADDOCK, P.T. The composition of copper alloys used by the Greek, Etruscan and Roman civilizations. 3 The origins and early use of brass. Journal of Archaeological Science, v. 5, n. 1, 1978.

CRADDOCK, P.T. Three thousand years of copper alloys: from the Bronze Age to the Industrial Revolution. In: APPLICATION OF SCIENCE IN EXAMINATION OF WORKS OF ART, [1984?], Boston (Museum of Fine Arts). Proceedings... Boston: P.A. England and L. Van Zelst, 1985. p. 59-67.

DEVOS, W.; MOENS, L.; Von BOHLEN, A.; KLOCKENKAMPER, R. Ultra-microanalysis of inorganic pigments on painted objects by total reflection x-ray fluorescence analysis. Studies in Conservation, [v.] 40, p. 153-162, 1995.

FERRETTI, M.; GUIDI, G.F.; MOIOLI, P.; SCAFÈ, R.; SECCARONI, C. The presence of antimony in some grey colours of three paintings by Correggio. Studies in Conservation, v. 36, n. 4, p. 235-239, 1991.

FERRETTI, M.; GUIDI, G.F.; MOIOLI, P.; SCAFÈ, R.; SECCARONI, C. L'impiego della fluorescenza X per indagini non-distruttive sui dipinti. Beni Culturali tutela e valorizzazione, v. 2, n. 6, p. 38-44, 1994.

FERRETTI, M.; MOIOLI, P.; SECCARONI, C. The apsidal stained-glass windows of Orvieto Cathedral: characterization of the materials. In: INTERNATIONAL CONGRESS ON SCIENCE AND TECHNOLOGY FOR THE SAFEGUARD OF CULTURAL HERITAGE IN THE MEDITERRANEAN BASIN, 2., 1999, Paris. Proceedings... Paris: [s.n.], 1999. p. 625-628. (Seminário realizado em Paris, de 5 a 9 de julho de 1999).

FERRETTI, M.; FORMIGLI, E.; LEPORE, L.; LO SCHIAVO, F.; MACNAMARA, E.; MICCIO, M.; PALMIERI, A.; PECCHIOLI, R.; ROMUALDI, A.; SHEFTON, B. The Trèstina Bronzes: Archaeometry and Archaeology. In: 
SYMPOSIUM ON ARCHAEOMETRY OF THE HELLENIC SOCIETY OF ARCHAEOMETRY, 4., 2003, Athens. Proceedings... Athens: [s.n.], 2008. p. 469-479. (Seminário realizado em Atenas, de 28 a 31 de maio de 2003).

FREESTONE, I.C. Looking into glass. In: BOWMAN, S., ed. Science and the Past, the Trustees of the British Museum. London: Butler \& Tanner, 1991. p. 37-56.

FREESTONE, I.C. Theophilus and the composition of medieval glass. In: MRS MEETING SYMPOSIA, 1992, San Francisco, CA. Materials Issues: Art and Archaeology III. Pittsburgh: MRS (eds. P.B. Vandiver, J.R. Druzik, G.S. Wheeler and I.C. Freestone), 1993. p. 739-746. v. 267.

GETTENS, R.J.; FITZHUGH, E. West. Azurite and Blue Verditer. Studies in Conservation, [v.]11, p. 54-61, 1966.

GETTENS, R.J.; KUHN, H.; CHASE, W. T. Lead White. Studies in Conservation, [v.]12, p. 125-139, 1967.

GILFRICH, J.V. Modern X-ray fluorescence analysis. Prog. Analyt. Spectrosc., [v.]12, p. 1-20, 1989.

HALL, E.T. Some uses of physics in archaeology. In: Year Book of the Physical Society. [S.I.]: [s.n.], 1958. p. 2234.

HALL, E.T. Surface-enrichment of buried metals. Archaeometry, [v.] 4, p. 62-66, 1961.

HALL, E.T.; ROBERTS, G. Analysis of the Moulsford Torc. Archaeometry, [v.] 5, p. 28-32, 1962.

HALL, E.T.; BANKS, M.S.; STERN, J.M. Uses of X-ray Fluorescence Analysis in Archaeology. Archaeometry, [v.] 7, p. 84-89, 1964.

HALL, E.T.; SCHWEIZER F.; TOLLER, P.A. X-ray fluorescence analysis of museum objects: a new instrument. Archaeometry, [v.] 15, p. 53-78, 1973.

HENDERSON, J. The scientific analysis of ancient glass and its archaeological interpretation. In: Scientific analysis in archaeology (ed. J. Henderson). Exeter: Short Run Press, 1989. p. 30-62.

JENKINS, R.; GOULD; R.W.; GEDCKE, D. Quantitative X-ray Spectrometry. 2. ed. New York: Marcel Dekker, 1995.

KELLEY, S.; WILLIAMS-THORPE, O.; THORPE, R.S. Laser argon dating and geological provenancing of a stone axe from the Stonehenge environs. Archaeometry, [v.] 36, p. 209-216, 1994.

KLOCKENKÄMPER, R.; BUBERT, H.; HASLER, K. Detection of near-surface silver enrichments on roman imperial silver coins by X-ray spectral analysis. Archaeometry, [v.] 41, p. 311-320, 1999.

KRAAY, C.M. The Composition of electrum coinage. Archaeometry, [v.] 1, p. 21-23,1958.

KÜHN, H. Lead-Tin Yellow. Studies in Conservation, [v.] 13, p. 7-33, 1968. 
LUTZ, J.; PERNICKA, E. Energy dispersive X-ray analysis of ancient copper alloys: empirical values for precision and accuracy. Archaeometry, [v.] 38, p. 313-323, 1996.

MALMQVIST, K.G. Comparison between PIXE and XRF for applications in art and archaeology. Nucl. Instr. and Meth., B 14, p. 86-92, 1986.

MILAZZO, M.; CICARDI, C. X-ray fluorescence characterization of the Corona Ferrea. Archaeometry,[v.] 40, p. 351-360, 1998.

MUHLETHALER, B.; THISSSEN, J. Smalt. Studies in Conservation, [v.] 14, p. 47-61,1969.

PALMIERI, A.; FRANGIPANE, M.; HUPTMANN, A.; HESS, K.; Early metallurgy at Arslantepe during the Late Chalcolithic and the Early Bronze Age IA-IB periods. In: DER ANSCHNITT BEIHEFT INTERNATIONAL CONFERENCE, 9., 1999. The Beginnings of Metallurgy. Bochum: [s.n.], 1995. p. 141-148.

PALMIERI, A.; Early smelting experiments in EBA I of Arslantepe (Turkey). In: INTERNATIONAL CONGRESS ON SCIENCE AND TECHNOLOGY FOR THE SAFEGUARD OF CULTURAL HERITAGE IN THE MEDITERRANEAN BASIN, 2., Paris, 1999. Proceedings... Paris: [s.n.], [1999?]. p. 259-262. (Conferência realizada em Paris, de 5 a 9 de julho de 1999).

PICON, M.; VICHY, M.; MEILLE, E. Composition of the Lezoux, Lyon and Arezzo Samian Ware. Archaeometry, [v.] 13, p. 191-208, 1971.

PICON, M.; CARRE, C.; CORDOLIANI, M.L.; VICHY, M.; HERNANDEZ, J.A; MIGNARD, J.L. Composition of the La Graufesenque, Banassac and Montans terra sigillata. Archaeometry, [v.] 17, p.191-199, 1975.

PLESTERS, J. Ultramarine Blue, Natural and Artificial. Studies in Conservation, [v.] 11, p. 62,1966.

RIEDERER, J. Die Metallanalyse. In: Ein Depot zerschlagener Grossbronzen aus Augusta Raurica (eds. B. Janietz Schwartz and D. Rouiller). Basel: BSB Buch Service, 1996. p. 120-143.

SCHNEIDER, G.; HOFFMANN, B.; WIRZ, E. Significance and dependability of reference groups for chemical determinations of provenance of ceramic artifacts. In: International Symposium On Archaeometry And Archaeological Prospection, 18., Bonn, 1978. Proceedings...(Conferência realizada em Bonn, de 14 a 17 de março de 1978). Publicado em: Archaeo-Physika, [v.] 10, 1980. p. 269-283.

SCHNEIDER, G. Bronze casting at Olympia in Classical times. MASCA Res. Pap. Sci. Archaeol, [v.] 6, p. 17-24, 1989.

SOPRINTENDENZA ARCHEOLOGICA PER LA TOSCANA - CENTRO DI RESTAURO. Relazione sulle analisi. Due Bronzi da Riace, Bollettino d'Arte, Serie Speciale n. 3, parte I. Roma: IPZS, p. 85-106, 1984.

STOLOW, N.; HANLAN, J.F.; BOYER, R. Element distribution in cross-sections of paintings studied by the X-ray macroprobe. Studies in Conservation, [v.] 14, p. 139-151, 1969. 
SUTHERLAND, C.H.V.; HAROLD, M.R. The silver content of Diocletian's early post-reform copper coins. Archaeometry, [v.] 4, p. 56-61, 1961.

WILLIAMS-THORPE, O. Obsidian in the Mediterranean and Near East: a provenancing success story. Archaeometry, [v.] 37, p. 217-248, 1995.

\section{Agradecimentos}

Agradeço a todos aqueles que, de algum modo, e em circunstâncias diversas, contribuíram para o desenvolvimento das pesquisas descritas neste artigo, em particular à Profa. C. Bartuli, ao Dr. A. Bottini, ao Sr. A.Calì, ao Prof. C. Caneva, ao Sr R. Costa, ao Arquebispo M. Costalunga, ao Prof. F. Felli, ao Conde P. Marzotto, ao Sr. C. Panzironi.Um particular agradecimento à Profa. A. Tirello que com grande amizade e paciência aceitou traduzir este artigo para o português, respeitando sua essência e significado.

\section{Crédito}

* Cientista senior do CNR - Istituto per le Tecnologie Applicate ai Beni Culturali.

e-mail: marco.ferretti@itabc.cnr.it

Tradução: Regina Andrade Tirello - Arquiteta. Especialista doutora em conservação e restauro do CPC-USP e docente da Faculdade de Engenharia Civil. Arquitetura e Urbanismo da Unicamp.

Título original: Principi e applicazioni dell'analisi XRF con strumentazione portatile. 